\title{
HORIZONTAL CELLS OF THE MOUSE RETINA CONTAIN GLUTAMIC ACID DECARBOXYLASE-LIKE IMMUNOREACTIVITY DURING EARLY DEVELOPMENTAL STAGES ${ }^{1}$
}

\author{
JUTTA SCHNITZER ${ }^{2}$ AND ANNE C. RUSOFF ${ }^{3}$ \\ Max-Planck-Institut für Hirnforschung, Deutschordenstrasse 46, D-6000 Frankfurt/M. 71, Federal Republic of Germany
}

Received November 14, 1983; Revised May 23, 1984; Accepted May 30, 1984

\begin{abstract}
We have used an antiserum to L-glutamic acid decarboxylase ((GAD), a synthesizing enzyme for $\gamma$ aminobutyric acid (GABA)) to localize putative GABAergic neurons in the developing C57BL/6J mouse retina. At early developmental stages (embryonic day 17 to postnatal day 3), strong GAD-like immunoreactivity is detectable in cell bodies located within the neuroblastic layer. These cells have relatively large cell bodies and extend several sturdy processes which are oriented radially at these early stages. We have identified these cells as horizontal cells. In addition, cell bodies adjacent to the inner plexiform layer and both diffuse and punctate structures within the inner plexiform layer proper have weak GAD-like immunoreactivity at this time. By postnatal day 6, GAD-positive horizontal cell processes begin to form a horizontal network in the newly formed outer plexiform layer. Immunolabeling of amacrine cell bodies and of punctate structures in the inner plexiform layer becomes much stronger at this time, reaching a maximum staining intensity during the second postnatal week. After postnatal day 12, GAD-like immunoreactivity of the horizontal cells begins to decline; in 4-weekold mice the horizontal cells are no longer detectably labeled by this GAD antiserum. At the same time, the GAD-like-immunoreactive material in the inner plexiform layer becomes stratified, forming distinct layers. Amacrine cells and the inner plexiform layer remain GAD positive into adulthood.
\end{abstract}

The amino acid $\gamma$-aminobutyric acid (GABA) is probably a neurotransmitter in the vertebrate retina. The uptake of $\left[{ }^{3} \mathrm{H}\right]$ GABA, demonstrated by autoradiography, suggests that subclasses of amacrine cells are GABAergic in rabbit (Ehinger, 1970; Ehinger and Falck, 1971; Marshall and Voaden, 1975), in rat (Marshall and Voaden, 1974a; Neal and Iversen, 1972), in mouse (Blanks and Roffler-Tarlov, 1982), and in cat retina (Nakamura et al., 1980, Pourcho, 1980). In these experiments Müller cells were also observed to accumulate [ $\left.{ }^{3} \mathrm{H}\right] \mathrm{GABA}$, especially if the uptake was performed in vitro and not in situ. In the frog (Hollyfield et al., 1979), pigeon and chicken (Marshall and Voaden, 1974b), and goldfish retina (Wu et al., 1981), horizontal cells as well as amacrine cells show high affinity GABA uptake. In these lower vertebrates, in contrast to mammals, Müller cells seem to lack a high affinity GABA uptake system.

With the development of specific antisera to $\mathbf{L}$-glutamic acid

\footnotetext{
${ }^{1}$ We are grateful to W. H. Oertel (Neurologische Klinik der Technischen Universität, Munich, Federal Republic of Germany) for his generous gift of antiserum to glutamic acid decarboxylase and for comments on the manuscript. We thank B. B. Boycott for his valuable suggestions during the initial phase of our studies, H. Wässle, L. Peichl, and J. Bolz for helpful discussions, G. Heiss and B. Schlei for technical assistance, and I. Odenthal and D. Czarniecki for typing the manuscript.

${ }^{2}$ To whom correspondence should be addressed.

${ }^{3}$ Permanent address: Department of Physiological Sciences, Oklahoma State University, Stillwater, Oklahoma 74078.
}

decarboxylase (GAD, EC 4.1.1.15), the rate-limiting enzyme in GABA synthesis, the visualization of GABAergic neurons at a much higher level of resolution became possible. Using these antisera, GAD was localized in horizontal and certain amacrine cells in the goldfish (Wu et al., 1981) and frog retina (Brandon et al., 1980). In the adult mammals studied so far, only amacrine cells contain GAD (Brandon et al., 1979, 1980; Vaughn et al., 1981; Wu et al., 1981; J. Bolz and N. Brecha, personal communication). In the absence of the definitive double-labeling experiments showing that one and the same cell contains the biosynthetic enzyme and possesses a high affinity uptake system, it has generally been assumed that $\left[{ }^{3} \mathrm{H}\right] \mathrm{GABA}$ autoradiography and GAD immunocytochemistry label the same neuronal cell classes. Recently, Zucker et al. (1983) have done such a double-labeling experiment with the goldfish retina and report that, in most cases, CrAD-immunoreactive amacrine cells fail to take up $\left[{ }^{3} \mathrm{H}\right] \mathrm{GABA}$. They suggest that in the goldfish retina the presence of GAD is a marker for GABA-releasing neurons whereas $\left[{ }^{3} \mathrm{H}\right]$ GABA uptake is not.

Recent studies of retinal development have shown that GABA uptake, synthesis, and release systems emerge at a precise temporal sequence during differentiation (Hollyfield et al., 1979; Lam et al., 1980; Fung et al., 1982). Since the presence of a GAD-like antigen seems to be a good indicator for GABAergic neurons, in the present study we have used an antiserum to GAD to examine the development of GABAergic neurons in the mouse retina. Since immunocytochemical data have the limitation that even a well characterized antibody may detect unknown cross-reactive molecules and thus lead to false-positive results, it is appropriate to refer to the immuno- 
reactivity which we found as "GAD-like." We have done so wherever this term was not too cumbersome. We chose to study the retina of the mouse because its development and synapse formation have been studied extensively (Sidman, 1961; Olney, 1968; Hinds and Hinds, 1974, 1978, 1979, 1983; Bhattacharjee, 1977, Blanks and Bok, 1977, Fisher, 1979a). We demonstrate here that horizontal cells contain GAD-like immunoreactivity during about 4 weeks of their development but lose this reactivity after the fourth postnatal week. In contrast, amacrine cells retain GAD-like immunoreactivity into adulthood.

\section{Materials and Methods}

Animals. We examined C57BL/6J mice at several developmental stages (number of animals studied in parentheses): embryonic day 17 (E17) (1), and postnatal days 0 (P0) (4), P3 (7), P6 (7), P9 (3), P12 (3), P21 (2), P28 (1), P32 (1), and during adult life (P60 to P120) (6). The day a vaginal plug was found was designated as embryonic day 0 (E19 $=$ birth $=\mathrm{P} 0$ ). The first animals of our colony were a gift of Dr. M. Schachner (Department of Neurobiology, Heidelberg University, Heidelberg, Federal Republic of Germany). All animals used in the present study were bred in our own animal facilities.

Antiserum to GAD. GAD antiserum S3 (provided by Dr. W. H. Oertel) was raised in sheep and characterized by immunoprecipitation and immunoelectrophoresis, as described in detail elsewhere (Oertel et al., 1981a, b). In brief, this antiserum recognized only one antigen in crossed immunoelectrophoresis with a 150 -fold purified GAD preparation from rat brain. Although it also precipitated the activity of cysteine sulfinic acid decarboxylase (CSD II), this enzymatic activity is considered to reside on the GAD molecule (Oertel et al., 1981b; Wu, 1982). The antiserum did not precipitate brain CSD I or liver CSD which are considered to be immunologically different from GAD/CSD II (Oertel et al., 1981b). (For further comparison of GAD antiserum $\mathrm{S} 3$ with other available GAD antisera, see Oertel et al. (1983)).

Although the enzyme GAD/CSD II has the potential to synthesize taurine as well as GABA, this possibility is very unlikely; the high $K_{\mathrm{M}}$ value $(6 \mathrm{mM})$ for this reaction would require a very high intracellular concentration of cysteine sulfinic acid (Oertel et al., 1981b). Oertel et al. (1981b) concluded that GAD/CSD II is exclusively involved in GABA synthesis.

Tissue fixation and sectioning. Two different modes of tissue fixation were used. $(a)$ In one procedure, animals were fixed by perfusion with freshly prepared $4 \%$ paraformaldehyde (Merck) in $0.1 \mathrm{M}$ sodium phosphate buffer, $\mathrm{pH} 7.4$. The eyes were removed, placed in fixative overnight at $4^{\circ} \mathrm{C}$, immersed in $30 \%$ sucrose for $24 \mathrm{hr}$ at $4^{\circ} \mathrm{C}$, and then embedded in gelatin and quickly frozen. $10-\mu \mathrm{m}$-thick vertical sections were cut on a cryostat (Jung), mounted, and dried onto chrome alum/ gelatin-covered coverslips. Sections were usually processed immediately for immunohistochemistry. Some sections were stored at $-70^{\circ} \mathrm{C}$ for several months without detectable loss of enzyme immunoreactivity. (b) In the other procedure, eyes were removed from ether-anesthetized, decapitated animals. After removal of the cornea, lens, and vitreous, the retina was removed from the eye cup and fixed with $4 \%$ paraformaldehyde. In some experiments $0.1 \%$ glutaraldehyde (Serva) was added to the fixative. The retinae were embedded in gelatin and fixed overnight in $4 \%$ paraformaldehyde at $4^{\circ} \mathrm{C}$. Horizontal and vertical sections, $50 \mu \mathrm{m}$, thick, were cut on a Vibratome (Oxford) into phosphate buffer. These sections were either processed immediately or were stored in phosphate buffer at $4^{\circ} \mathrm{C}$ for up to 2 weeks without detectable loss of immunoreactivity.

Staining. For the immunocytochemistry we used the unlabeled antibody enzyme method of Sternberger (1979) as modified by Oertel et al. (1981c). Between each step, sections were washed in phosphate buffer. The procedure follows, in brief. (1) sections were treated with $3 \%$ hydrogen peroxide $/ 10 \%$ methanol in phosphate buffer for 5 min at room temperature. (2) Incubation for $1 \mathrm{hr}$ at room temperature in a mixture of $1 \mathrm{M}$ DL-lysine monohydrochloride (Sigma), $0.5 \%$ Triton X100 (Merck), and $10 \%$ normal rabbit serum in phosphate buffer followed. (3) The GAD antiserum was applied to the sections at a dilution of $1: 1000$ or 1:2000, and they were incubated at $4^{\circ} \mathrm{C}$ for 12 to $20 \mathrm{hr}$. All antibody dilutions were carried out in $3 \%$ normal rabbit serum in phosphate buffer; $0.5 \%$ Triton X-100 was also added sometimes. For controls GAD antiserum was replaced by normal sheep serum diluted to $1: 1000$ to $1: 2000$. (4) The sections were incubated for $1 \mathrm{hr}$ at room temperature with the immunoglobulin fraction of rabbit anti-sheep serum (Miles-Yeda) diluted 1:50. (5) Sections were incubated for $1 \mathrm{hr}$ at room temperature with goat peroxidase/antiperoxidase complex (Miles-Yeda) diluted 1:100. (6) The sections were then incubated with $0.05 \% 3,3^{\prime}$-diaminobenzidine tetrahydrochloride (DAB) (Sigma) in phosphate buffer for $5 \mathrm{~min}$, followed by $0.05 \% \mathrm{DAB}$ dissolved in $0.01 \%$ hydrogen peroxide in phosphate buffer for 8 to $10 \mathrm{~min}$. After washing, some Vibratome sections were mounted on chrome alum/gelatin-covered slides, air dried, as were cryostat sections, dehydrated, and covered with Permount. Other Vibratome sections were treated with $1 \%$ osmium tetroxide for $90 \mathrm{~min}$ after the $\mathrm{DAB}$ reaction, washed, dchydrated with ethanol and propylene oxide, and embedded in Epon. Semithin sections of these Vibratome sections were cut on an Ultratome $\mathrm{V}$ (LKB), collected, and counterstained with dilute toluidine blue. Sections were examined and photographed on a Zeiss photomicroscope II.

In some experiments, GAD was localized by immunofluorescence. In these cases, treatment with hydrogen peroxide/methanol was omitted, but incubation with DL-lysine and GAD antiserum was carried out, as described. Incubation with the immunoglobulin fraction of rabbit antisheep serum conjugated to fluorescein isothiocyanate (Miles-Yeda) diluted 1:50 to 1:100 followed. Sections were coverslipped with phosphate buffer/glycerol (1:1, v:v) and examined with a Zeiss ICM 405 inverted fluorescence microscope.

\section{Results}

We began our study on mice at E17 since the retina of the mouse first has a trilaminar structure on this day (Hinds and Hinds, 1978): postmitotic ganglion cells form the ganglion cell layer which is separated from the neuroblastic layer by a thin, almost cell-free zone, the developing inner plexiform layer. At this time the neuroblastic layer contains amacrine, bipolar, horizontal, and photoreceptor cells and their precursors. GADlike immunoreactivity is detectable in two different parts of the E17 retina-in the developing inner plexiform layer (Fig. 1B) and in a few cell bodies located in the outer third of the neuroblastic layer (Fig. $1 \mathrm{~A}$, arrows). The staining of these cell bodies and of their processes is very prominent. The cytoplasm, but not the nucleus, of these cells is GAD positive; the cytoplasm is concentrated on their scleral pole. The majority of the processes of these cells are radially oriented, and many are very long. Generally a single process extends from the vitreal side of the cell toward the inner plexiform layer and may sometimes even reach the inner plexiform layer; two or more bifurcated processes arise from the scleral pole of the cell and approach very close to the external limiting membrane (Fig. $1 B$ ). Although we did not systematically compare different regions of the retina, some areas of the retina appear to contain fewer GAD-positive cells with radially oriented processes than others.

At birth the GAD-like immunoreactivity of the inner plexiform layer is slightly more intense than al E17. In addition, cell bodies of the neuroblastic layer adjacent to the inner plexiform layer exhibit weak GAD-like immunoreactiity (Fig. 2B). Again, GAD-positive cells in the outer third of the neuroblastic layer are prominent (Fig. 2A). Their cell bodies are scattered throughout the outer third of the neuroblastic layer. Their GAD-positive cytoplasm is still concentrated at their scleral pole, and several sturdy processes with a radial orientation arise there. Not as many cells have processes extending toward the plexiform layer as at E17. However, many cells do still have these processes, and the processes often form "loops" extending from the cell body toward the inner plexiform layer and then turning back toward the external limiting membrane (Fig. 2A, arrow).

By P3 the GAD-like immunoreactivity of the cytoplasm of the cclls lying in the neuroblastic layer adjacent to the inner plexiform layer is considerably stronger than at P0 (Fig. $3 B$ ). In the inner plexiform layer many dot-like, punctate structures are stained. The morphological appearance of the GAD-positive cells located in the outer third of the neuroblastic layer is similar to their appearance in the neonatal mouse. However, they are no longer scattered across the outer third of the 

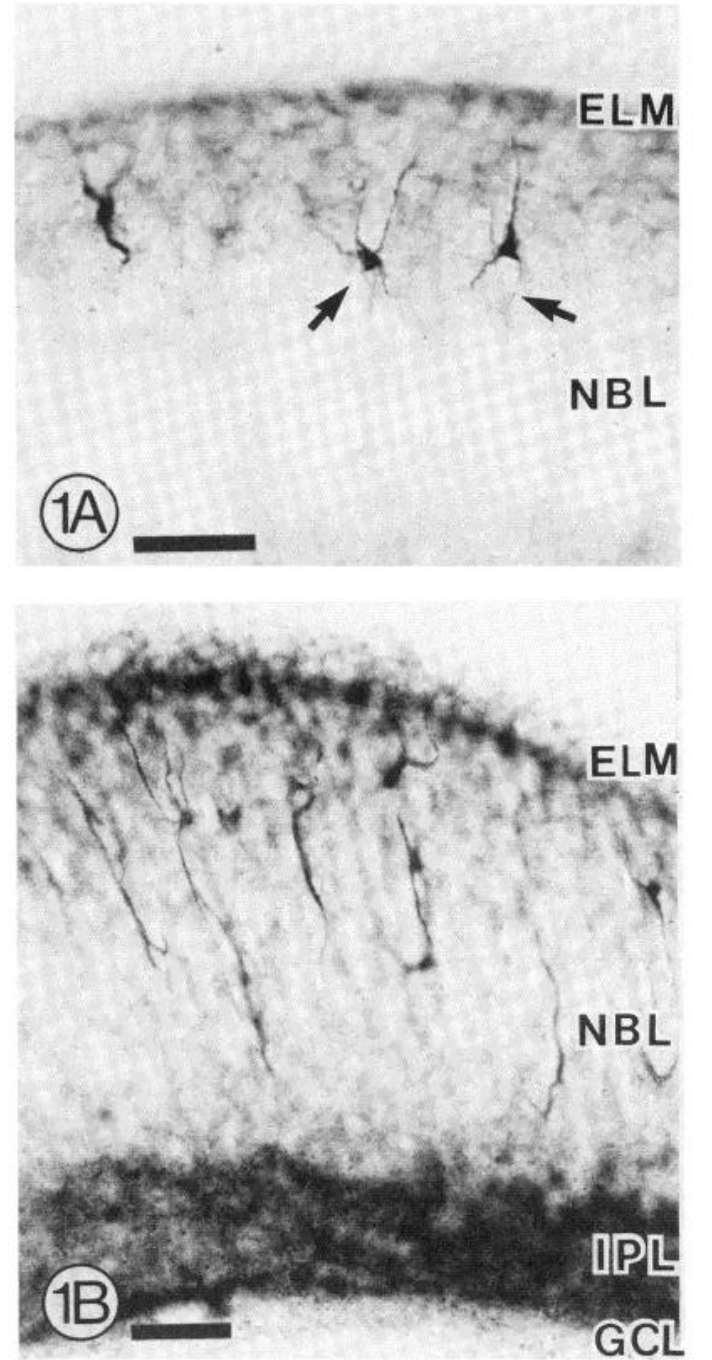

Figure 1. GAD-positive cells in vertical sections of the retina from a mouse at E17. Sections are $50 \mu \mathrm{m}$ thick, but staining is confined to the surface 5 to $10 \mu \mathrm{m}$ since antibodies only penetrated this far in these Vibratome sections. A, Cell bodies and processes located in the outer third of the neuroblastic layer $(N B L)$ are labeled (arrows). Note the heavily stained cellular processes leading to the external limiting membrane $(E L M) . B$. Radially oriented processes traversing the entire neuroblastic layer are a typical feature at this developmental stage. Their cell bodies are difficult to resolve since they often are deeper in the section than the antibodies penetrate. The inner plexiform layer $(I P L)$ is detectably labeled. $G C L$, ganglion cell layer. Bars represent 20 $\mu \mathrm{m}$.

neuroblastic layer but instead have formed a single row. These cells are still polarized with most of the GAD-positive cytoplasm at the scleral pole of the cell, giving rise to several radially oriented processes which extend toward the external limiting membrane (Fig. 3). Only few of these cells have detectable processes which extend toward the inner plexiform layer.

Between P3 and P6 a very thin, cell-free zone, the outer plexiform layer, becomes visible separating the neuroblastic layer into an inner and an outer nuclear layer. The strongly GAD-positive cell bodies which earlier were in the outer third of the neuroblastic layer are now located at the scleral border of the inner nuclear layer adjacent to the outer plexiform layer (Fig. 4, $A$ and $B$ ). Their processes, which were radially oriented at earlier times, now become horizontally oriented and are mainly confined to the outer plexiform layer. The morphological appearance and location of these cells within the retina
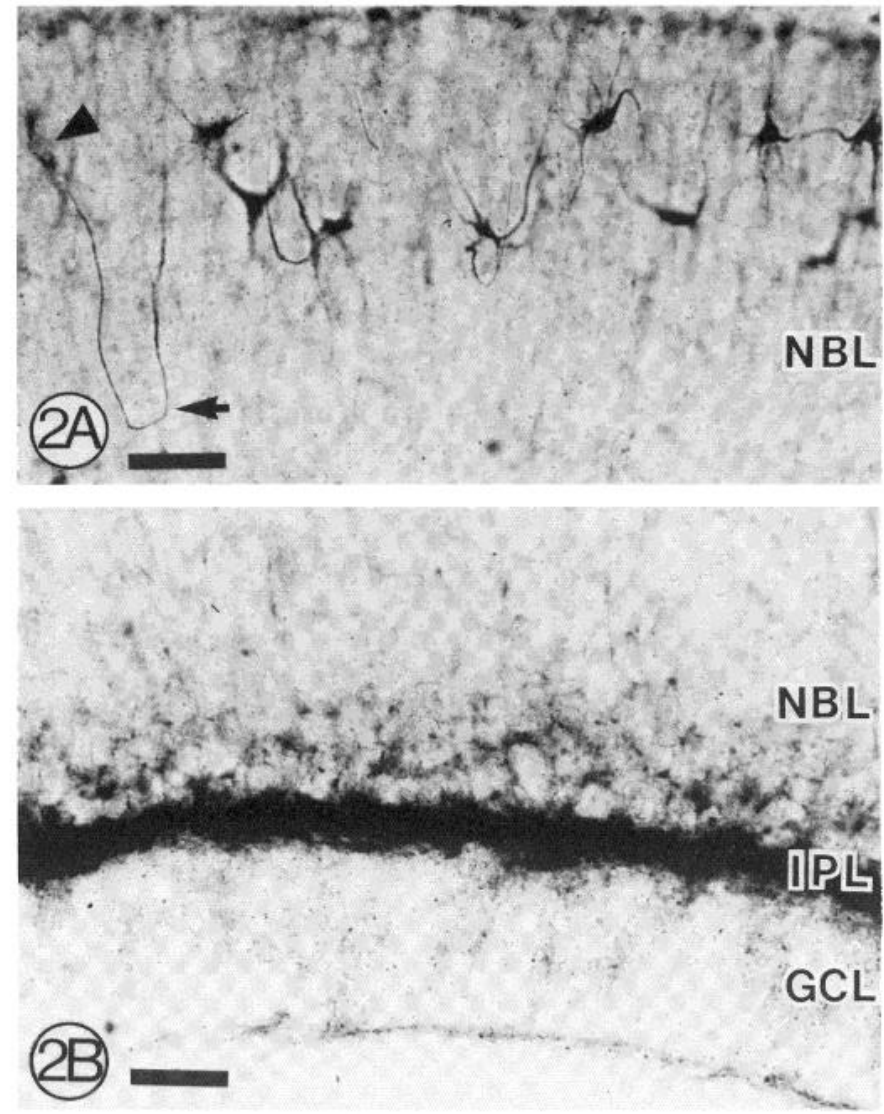

Figure 2. Immunocytochemical localization of GAD in $50-\mu \mathrm{m}$ thick vertical sections from the retina of a newborn mouse. $A$, Prominently labeled horizontal cells are scattered throughout the outer part of the neuroblastic layer $(N B L)$. The arrow indicates a cellular process which forms a "loop," arising from a horizontal cell body (out of focus) at the position indicated by the arrowhead, extending toward the inner plexiform layer and then looping back toward the external limiting membrane. Several other smaller "loops" are visible in this photograph. $B$, The inner plexiform layer (IPL) is GAD positive, and labeling is scattered over cell bodies located in the neuroblastic layer adjacent to the inner plexiform layer. $G C L$, ganglion cell layer. Bars represent 20 $\mu \mathrm{m}$.

leave no doubt that they are horizontal cells. Although we made no attempt to quantitate it, we often observe a "gradient" of developmental stages of horizontal cells between the peripheral and central part of the same vertical section from a P6 mouse retina. Horizontal cells located close to the optic nerve head appear as described above, with horizontally oriented processes. GAD-positive horizontal cells close to the ora serrata are more similar to those seen in the P3 mouse retina in that their processes are still mainly radially oriented.

When comparing neighboring horizontal cells, we observed no obvious differences between cells. Therefore, we wanted to know whether all horizontal cells in the mouse retina are GAD positive at this stage or whether we were only staining a certain class of horizontal cells. In an attempt to examine the twodimensional distribution of GAD-positive horizontal cells, we prepared $50-\mu \mathrm{m}$ thick horizontal sections through the whole retina. Part of one such section from a $\mathrm{P} 6$ mouse retina is shown in Figure $4 C$. GAD-positive horizontal cell processes form a dense network within the outer plexiform layer. Unfortunately, the antibodies which we used only penetrate 5 to 10 $\mu \mathrm{m}$ from each surface of the section so that probably all GADpositive processes are not stained, and it was very difficult to trace these cellular processes back to their cell bodies, lying in the inner nuclear layer deeper in the section. Therefore, we 

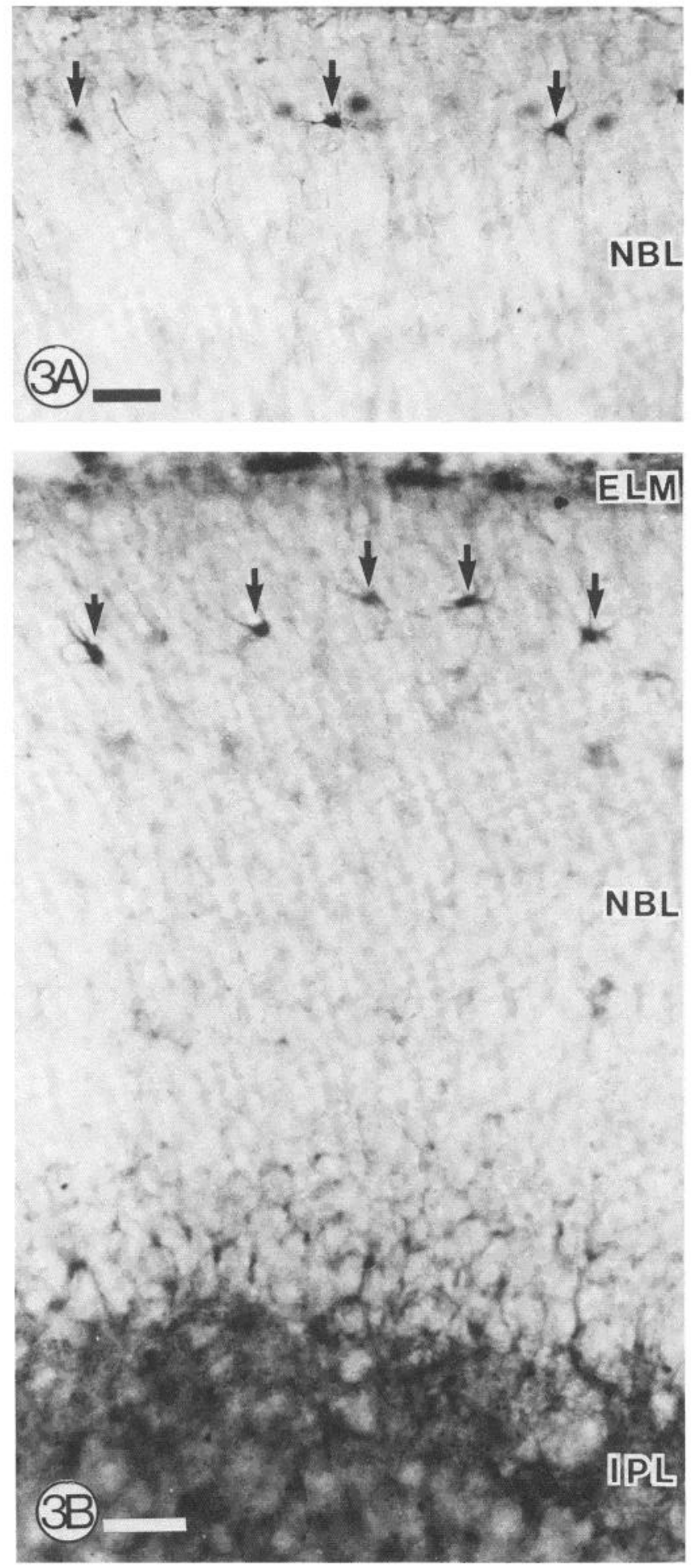

Figure 3. Immunohistochemical localization of GAD in $50-\mu \mathrm{m}$ thick sections from the retina of a mouse at P3. A, Horizontal cells (arrows) are approximately confined to one cell row. Most of the GAD-positive cytoplasm is at the scleral pole of the cell body; several processes arise there. GAD-positive horizontal cells on the opposite side of the section appear as fuzzy, dark dots near these cells. $B$, The inner plexiform layer $(I P L)$ and adjacent cell rows are also GAD positive. Here the horizontal cells are prominent (arrows) but slightly out of focus. ELM, external limiting membrane; $N B L$, neuroblastic layer. Bars represent $20 \mu \mathrm{m}$.
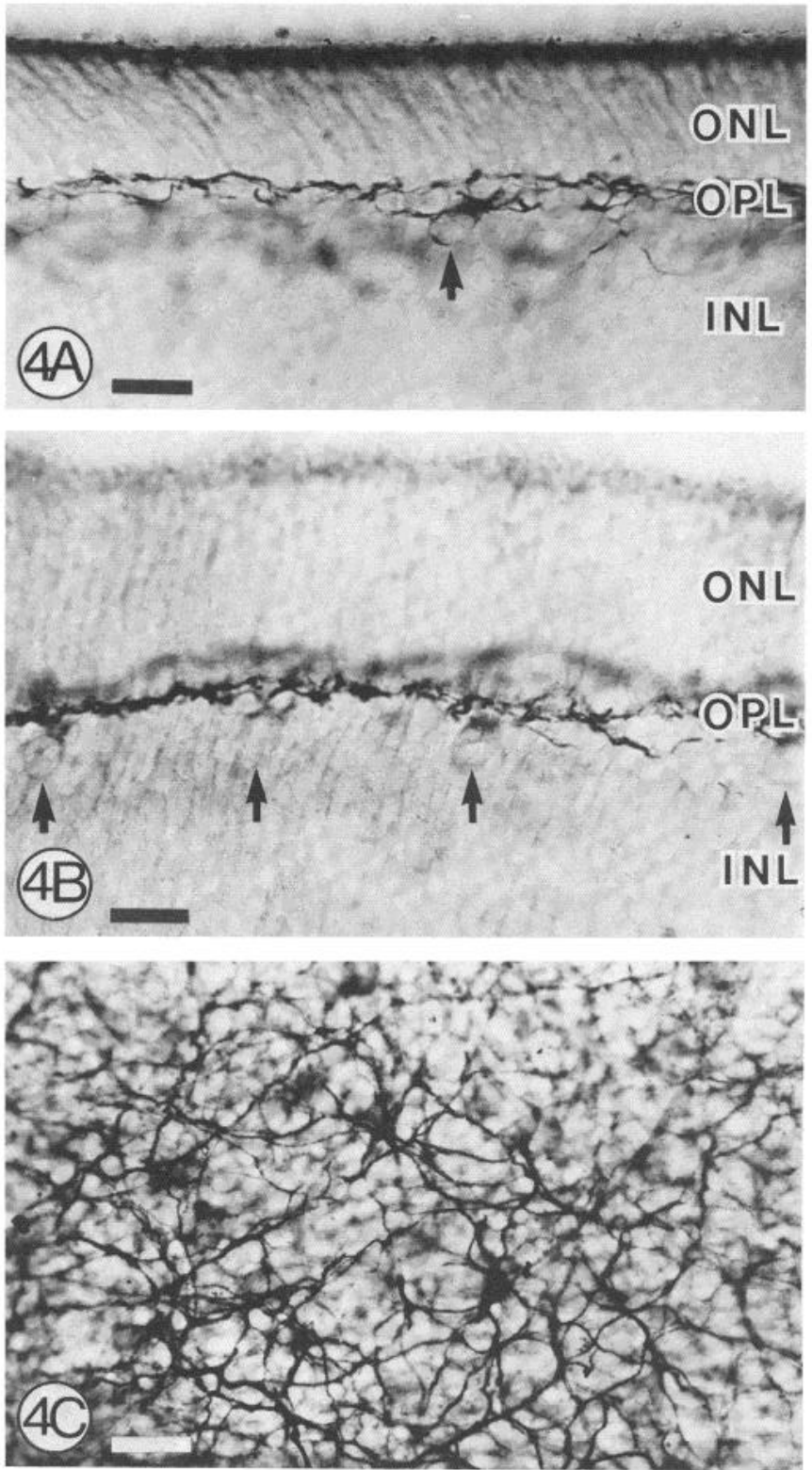

Figure 4. Immunohistological localization of GAD in $50-\mu \mathrm{m}$ thick sections from the retina of a mouse at $\mathrm{P} 6$. $A$ and $B$, Vertical sections. Horizontal cell bodies are GAD positive (arrows); their horizontally oriented processes extend within the developing outer plexiform layer $(O P L)$ and form a layer which visibly separates the outer and inner nuclear layers $(O N L$ and $I N L)$. Note that the horizontal cell bodies are located in the inner nuclear layer adjacent to the outer plexiform layer. The dark structures out of the plane of focus are GAD-positive horizontal cell bodies and their processes labeled on the opposite side of the section. $C$, Horizontal section through the outer plexiform layer Note the dense network of GAD-positive cellular processes; their cell bodies are out of focus. Bars represent $20 \mu \mathrm{m}$.

cannot determine from this material whether all horizontal cells are GAD positive at this stage, but from the density of GAD-positive processes we can estimate that at least a very large percentage of the horizontal cells must indeed be GAD positive.

At P6 the GAD antiserum also strongly labels punctate structures in the inner plexiform layer and the cytoplasm of adjacent cell bodies of amacrine cells. These GAD-positive amacrine cells are not confined to the innermost cell row adjacent to the inner plexiform layer, but are also located at some distance into the inner nuclear layer. Although we could 
not trace processes from individual amacrine cells into the inner plexiform layer in vertical sections, in horizontal sections through the inner plexiform layer we could resolve many thin, individual GAD-positive processes among speckly or punctate immunoreaction products.

By P9, GAD-positive horizontal cell processes are horizontally oriented in all parts of the retina (Fig. 5). The horizontal cell bodies, however, are often difficult to resolve. In contrast, staining of amacrine cell bodies is quite strong. In the inner plexiform layer the immunoreactive material is beginning to be segregated into several GAD-positive bands; these bands are obscured by the density of the staining in the $50-\mu \mathrm{m}$ section shown in Figure 5 , but in $1-\mu$ m sections these bands appear similar to the bands seen in the adult (Fig. 6B).

From P12 onward, horizontal cell processes seem to lose GAD-like-immunoreactive material gradually. In vertical sections GAD-positive horizontal cell processes seem to be less intensely labeled compared to those in younger animals. In horizontal sections through the outer plexiform layer, GADpositive processes are obviously fainter and less numerous. In addition, small areas of the outer plexiform layer are almost free of GAD-positive processes. Amacrine cells and the inner plexiform layer continue to show prominent GAD-like immunoreactivity .

By P21, horizontal cell bodies and processes show even less GAD-like immunoreactivity than at P15. In horizontal sections the network of GAD-positive horizontal cell processes is even less dense than on the retina from P15. Many areas of the outer plexiform layer lack GAD-positive processes, and the remaining GAD-positive processes in the outer plexiform layer are very faint. By P28, horizontal cell immunoreactivity is almost indistinguishable from nonspecific background labeling.

From P32 onward, no horizontal cells are visibly GAD immunoreactive. Although in thick vertical sections the labeling of the outer plexiform layer is higher than in adjacent parts of the inner nuclear layer and outer nuclear layer (Fig. 6A), no cellular staining is detectable in horizontal sections through the outer plexiform layer. In control sections obtained by replacing GAD antiserum with normal sheep serum, the outer plexiform layer of the adult mouse is always labeled slightly more than the adjacent nuclear layers, suggesting that the

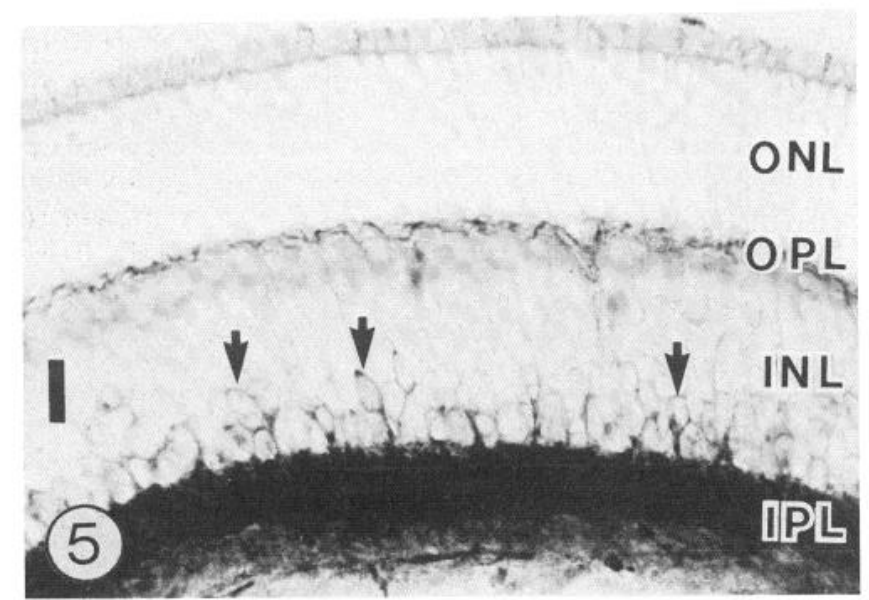

Figure 5. Immunocytochemical localization of GAD in a $50-\mu \mathrm{m}$ thick vertical section from the retina of a mouse at P9. Horizontal cell processes form a dense band in the outer plexiform layer $(O P L)$. The inner plexiform layer $(I P L)$ is strongly GAD positive. The GADpositive amacrine cells are not confined to the cell row adjacent to the inner plexiform layer but are also present more sclerally in the inner nuclear layer $(I N L$; arrows). Note that their processes extend only to the inner plexiform layer. $O N L$, outer nuclear layer. The bar represents $20 \mu \mathrm{m}$.
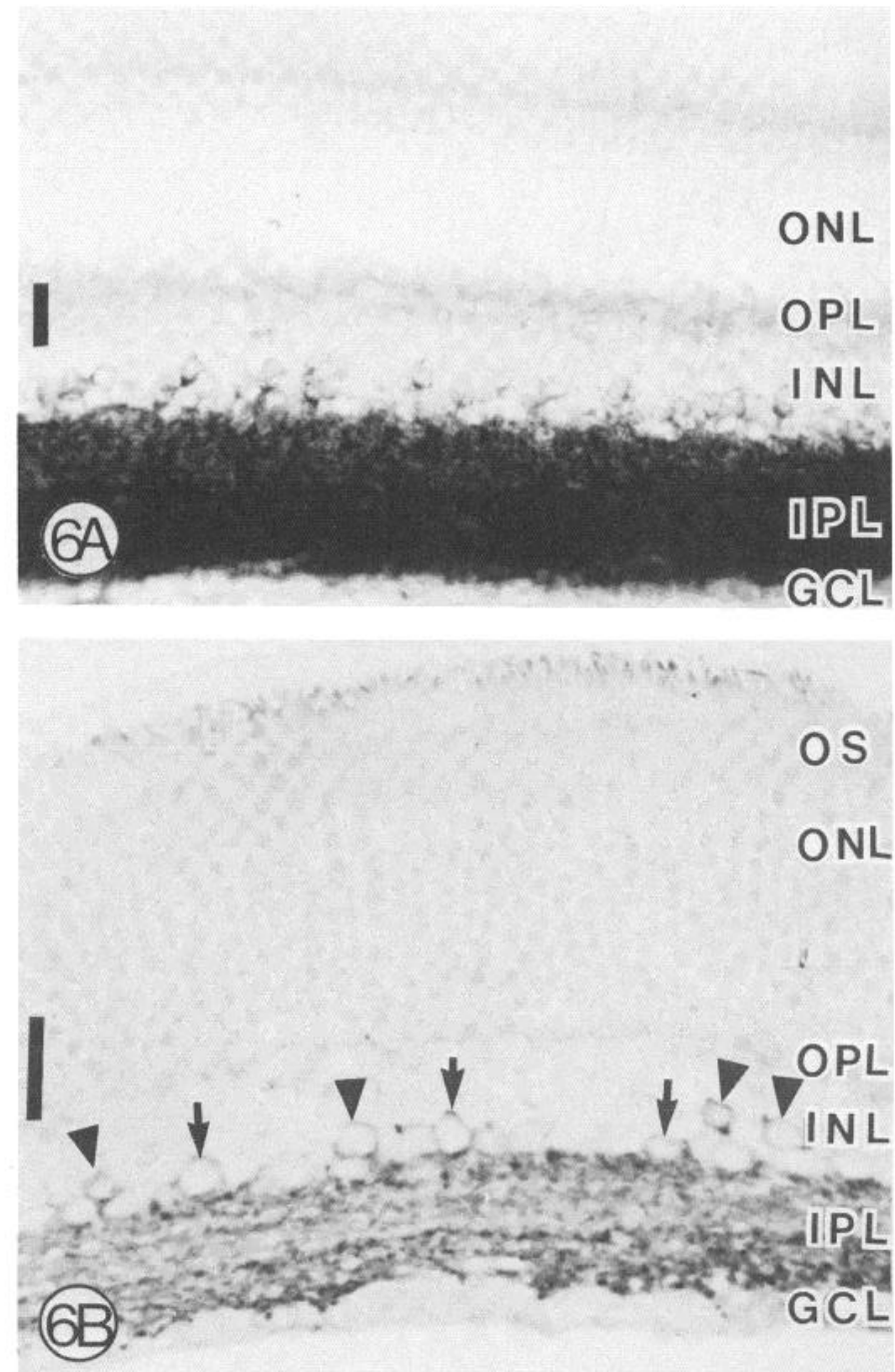

Figure 6. Immunocytochemical localization of GAD in a $50-\mu \mathrm{m}$ thick $(A)$ and a $1-\mu \mathrm{m}$ semithin $(B)$ vertical section from the retina of an adult mouse. $A$, The inner plexiform layer $(I P L)$ and amacrine cells are strongly GAD positive. Although the outer plexiform layer $(O P L)$ is darker than the adjacent cell rows, this labeling is not confined to any cellular elements and is probably nonspecific. $B$, The inner plexiform layer appears to contain several bands. Some GAD-positive amacrine cells are located close to the inner plexiform layer (arrows) but others are in the middle of it (arrowheads). The outer plexiform layer is completely GAD negative. $G C L$, ganglion cell layer; INL, inner nuclear layer; $O N L$, outer nuclear layer; $O S$, photoreceptor outer segments. Bars represent $20 \mu \mathrm{m}$.

labeling of the outer plexiform layer in the adult is indeed nonspecific. In addition, in semithin (1- $\mu$ m-thick) sections from retinae of adult mice, the outer plexiform layer lacks GAD-like immunoreactivity (Fig. $6 B$ ). In contrast to the loss of GADlike immunoreactivity by horizontal cells, the GAD-like immunoreactivity of amacrine cell bodies and of the inner plexiform layer remains unaltered into adulthood. GAD-positive amacrine cells are found both in the innermost and the middle parts of the inner nuclear layer, and the inner plexiform layer continues to have several GAD-positive laminae (Fig. 6B). Although we have looked for GAD-positive cells in the ganglion cell layer, we have found few in our material.

The presence of GAD-like immunoreactivity material in horizontal cells at early stages and its loss at later stages can be demonstrated with both the peroxidase-antiperoxidase technique and indirect immunofluorescence. The addition or ab- 
sence of Triton X-100 during antibody incubation does not affect horizontal cell staining. However, addition of $0.1 \%$ glutaraldehyde to the fixative ( $4 \%$ paraformaldehyde) greatly reduces the labeling of horizontal cells in young animals in a time-dependent manner. Fixation for 10 min reduces the staining intensity tremendously; after fixation for $90 \mathrm{~min}$, horizontal cells are GAD negative. In contrast, labeling of the inner plexiform layer is still visible after the latter fixation time in the presence of glutaraldehyde. When retinae obtained from mice older than $\mathrm{P} 8$ are fixed by immersion and not by perfusion, red blood cells carry detectable label after peroxidase reaction. This label is due to endogeneous peroxidase, since it is also observed in control sections.

\section{Discussion}

The present study was undertaken to follow the emergence and maturation of GAD-like immunoreactivity in the mouse retina. In the rabbit and the frog retina GABAergic properties appear in a precise and constant temporal pattern during retinal differentiation. The GABA uptake system is established first, followed by an increase in the activity of GAD, the ratelimiting enzyme in GABA synthesis, and, finally, the potassium-stimulated GABA release system increases (Hollyfield et al., 1979; Lam el al., 1980; Fung et al., 1982). Since Zucker et al. (1983) have suggested that the presence of GAD in a neuron is one of the better markers for a GABA-releasing neuron, the immunocytochemical demonstration of GAD seemed to us to be a good indicator of the development of GABAergic neurons in the mouse retina.

$G A D$-like immunoreactivity of amacrine cells and of the inner plexiform layer. We began our study of the development of the mouse retina with $\mathrm{E} 17$, since it is the first day that formation of the inner plexiform layer clearly separates postmitotic ganglion cells from the future photoreceptor, horizontal, bipolar, amacrine, and mitotic ventricular cells (Hinds and Hinds, 1978). We expected that this layering would enable us to correlate GAD-like immunoreactivity with retinal neuronal cell types. Indeed, at E17, weak, diffuse GAD-like immunoreactivity is found in the inner plexiform layer and in cell bodies located in the neuroblastic layer close to the inner plexiform layer. Whereas some amacrine cells cease dividing before E17 (Sidman, 1961) and start to differentiate (Hinds and Hinds, 1978, 1983), amacrine cell production continues until postnatal day 1 in central retina and postnatal day 5 in peripheral retina (Blanks and Bok, 1977). Our observation that GAD-like immunoreactivity increases gradually in cells in the vicinity of the inner plexiform layer between E17 and the second postnatal week is complementary to the time frame of amacrine cell production and differentiation. From the second postnatal week GAD-like immunoreactivity then remains unaltered into adulthood. Interestingly, these labeled cells are not confined to the cell row closest to the inner plexiform layer. Many cells are located in the second cell row scleral from the inner plexiform layer, as can be seen unequivocally in Figure $6 B$ (arrowheads). GAD-positive cells are observed in this position not only during development, when amacrine cells might not be located in their final positions, but also in the adult. We never observed a process extending from one of these cells toward the outer plexiform layer; generally we observed a single process extending from these cells toward the inner plexiform layer. These cells resemble a type of amacrine cell described in the ground squirrel retina by West (1976). Therefore, we suggest that the GAD-positive cells seen in our material in the vitreal half of the inner plexiform layer are amacrine cells. We suggest further that they are not interplexiform cells, despite the known presence of the cell bodies of interplexiform cells in this part of the mouse retina (Fisher, 1979b), since we never observe a process extending toward the outer plexiform layer. Vaugh et al. (1981) describe similarly located GAD-positive amacrine cells in the rat retina. We found very few GAD-positive cells in the ganglion cell layer of the mouse retina; this finding agrees with the apparent complete absence of displaced, GAD-positive amacrine cells in rat retina (Vaughn et al., 1981) but is in contrast to the numerous GAD-positive cells in the ganglion cell layer of the cat retina (J. Bolz and N. Brecha, personal communication). Thus, there is a striking species difference in GAD distribution in the retina.

The amount of GAD-like-immunoreactive material in the inner plexiform layer increases continuously during development, reflecting amacrine cell differentiation. At birth the GAD-like immunoreactivity in the inner plexiform layer is still weak and diffuse, but a few punctate structures can already be observed. During the first postnatal week, GAD-like immunoreactivity becomes more pronounced, and fine cellular processes can be resolved in horizontal sections cut through the inner plexiform layer. Distinct GAD-positive bands interrupted by more weakly reactive laminae first become visible in the inner plexiform layer around P9. These bands become more pronounced between P14 and P17 and remain present and distinguishable into adulthood.

Our immunocytochemical study clearly demonstrates that the amount of GAD-like immunoreactivity material in ama crine cell bodies and in their cellular processes increases during development of the mouse retina. Interestingly, GAD-like immunoreactivity in amacrine cell processes reaches its plateau during the second postnatal week, which is also the time at which establishment of synapses in the inner plexiform layer begins to plateau (Fisher, 1979a). Our results, additionally, confirm biochemical measurements of increasing GAD activity during retinal development of rabbit (Lam et al., 1980; Fung et al., 1982) and frog retina (Hollyfield et al., 1979).

GAD-like immunoreactivity in horizontal cells changes during development. In addition to amacrine cells, we have detected a second GAD-immunoreactive neuronal cell type in the developing mouse retina-the horizontal cell. At E17 a few GADpositive cells are located in the outer third of the neuroblastic layer. More of these cells are present at P0 and P3. The morphology of these cells and their position in the outer third of the neuroblastic layer are identical to the morphology and position of immature horizontal cells described by Ramón $y$ Cajal (1960). The sequence of transformation of the processes of these GAD-positive cells from their initial radial orientation to their final horizontal orientation exactly parallels that described by Ramón y Cajal (1960) for the processes of horizontal cells. Around P6, all stages of horizontal cell morphology are visible in the same section. More mature looking horizontal cells lie closer to the optic nerve head and the more immature ones lie closer to the ora serrata. Shaw and Weber (1983) reported that horizontal cell processes positive for neurofilaments first appear around birth in the rat retina. They also reported that the horizontal cell processes at this stage were distributed in vertical sections in "a rather disorganized manner throughout the outer third of the developing retina;" their observations thus agree with our observations in the early postnatal mouse. The morphology of GAD-positive horizontal cell processes as seen in horizontal sections of the outer plexiform layer from retinae of $\mathrm{P} 6$ mice resembles the morphology of horizontal cell processes in the adult mouse retina stained for neurofilaments (Dräger, 1983) and of the silver-stained horizontal cells described in the cat (Wässle et al., 1978).

GAD-like immunoreactivity, unlike neurofilament staining, is only a transient property of horizontal cells in the mouse retina. Around birth the horizontal cells contain considerably more GAD-like immunoreactivity material than do the amacrine cells, although eventually the amacrine cells will stain just as intensely as the horizontal cells did at their peak of 
immunoreactivity. This time disparity is probably largely the result of the earlier time of birth of horizontal cells-most horizontal cells are born before E17 (Sidman, 1961; Hinds and Hinds, 1983), whereas amacrine cells continue to be born until the second postnatal week (Blanks and Bok, 1977). Thus, horizontal cells are postmitotic and ready to differentiate before most amacrine cells are born. That horizontal cells do differentiate before amacrine cells is suggested by Olney's (1968) description of synapse formation in the outer plexiform layerthe layer in which horizontal cells are involved in synapsesprior to synapse formation in the inner plexiform layer-the layer in which amacrine cells are involved in synapses. However, the early development of GAD-like-immunoreactive material in horizontal cells cannot be strictly related to synapse formation since Olney's (1968) earliest unequivocal identification of horizontal cell synapses on bipolar cells in the mouse retina was on P10, more than 12 days after the onset of GAD detectability and only shortly before the beginning of the decline of GAD-like immunoreactivity in horizontal cells. This decline in immunoreactivity is observed by the beginning of the third postnatal week; after P32, no detectable amounts of GAD-like immunoreactivity material can be observed in horizontal cells.

Role of GAD during retinal development. Thus, we are left with two interrelated and intriguing questions: (1) is the GADlike-immunoreactive material in the horizontal cells the same as the immunoreactive material in the amacrine cells? and (2) what is the function of the GAD-like-immunoreactive material transiently present in the horizontal cells?

Since amacrine cells in many species are known to contain GAD (Brandon et al., 1979; 1980; Vaughn et al., 1981; Wu et al., 1981; J. Bolz and N. Brecha, personal communication) and since the GAD antiserum S3 differentially labels these cells in the developing and mature mouse retina as well as differentially labeling other known GABAergic neurons (horizontal cells in the adult goldfish retina-J. Schnitzer, unpublished observations), it is likely that the GAD-like-immunoreactive material in the developing amacrine cells of the mouse retina is indeed GAD. If the immunoreactive material in the amacrine and horizontal cells is the same, then these experiments demonstrate that mouse horizontal cells contain GAD during a transient phase of their development. To our knowledge this is the first suggestion that a mammalian horizontal cell contains $\mathrm{GAD}$, the rate-limiting enzyme in GABA synthesis, and may, therefore, be GABAergic (see Ehinger, 1982, for a recent review on GABAergic retinal neurons). We must stress that we are not claiming at this point that mouse horizontal cells are capable of synthesizing and using GABA as their neurotransmitter. Our own data (J. Schnitzer, unpublished observations) agree with those of Blanks and Roffler-Tarlov (1982), that adult mouse horizontal cells lack a high affinity GABA uptake system. We do not know yet whether the GAD-positive horizontal cells found at early developmental stages possess a high affinity GABA uptake system. However, the results of Zucker et al. (1983) suggest that the more appropriate question is not whether these neurons are capable of taking up GABA but whether they can synthesize it. This, too, remains for the future.

If GABA is indeed a horizontal cell transmitter at early but not at late developmental stages, then it is possible that horizontal cells have the capacity to switch from one transmitter to another during ontogenesis. To our knowledge this would be the first case described in which a neuron in the central nervous system switched from one transmitter to another, although this phenomenon has been described in the peripheral nervous system (Le Douarin et al., 1978; Patterson, 1978; Landis and Keefe, 1983).

A further possibility is that the G $\Lambda \mathrm{D}$ - like immunoreactivity does correctly demonstrate that the horizontal cells synthesize
GABA, but that GABA may not be a transmitter in these neurons, instead possibly playing a "neurotrophic role" during early retinal development and differentiation, promoting organization and layering of neuronal elements. This role might no longer be necessary at later stages, so that GABA synthesis might cease. This possibility is strengthened by the presence of strong GAD-like immunoreactivity in the horizontal cells shortly after they can be differentiated from other neurons and from the cells still in the mitotic cycle around them, and many days before the appearance of their first clear synapses onto bipolar cells (Olney, 1968). Madtes and Redburn (1983) have shown that GABA plays a "trophic role" in the rabbit retina during development by inducing the appearance of postsynaptic GABA receptors. It remains to be seen whether GABA plays a similar role in the developing mouse retina.

Another possibility is that the GAD-like-immunoreactive material in the horizontal cells is not the same as the immunoreactive material in the amacrine cells and is not related to GAD at all but represents an unknown cross-reactive material. This possibility cannot be ruled out by the immunological approach used here and is strengthened by the differential sensitivity to glutaraldehyde fixation between the GAD-like immunoreactivity in horizontal cells and in amacrine cell processes in the inner plexiform layer. Although this differential sensitivity may indicate that different molecules are being labeled in the different cell types, this is not necessarily true. Oertel et al. (1981c) reported that addition of glutaraldehyde to the fixative generally reduced the apparent reactivity of GAD antiserum S3 with neurons. The staining of cell bodies and dendrites was nearly, if not completely, abolished, whereas that of axons was much less affected. This is similar to the sensitivity which we observed-the cell bodies and dendrites of horizontal cells were no longer stained, whereas the inner plexiform layer remained stained. Even if the GAD-like immunoreactivity of horizontal cells represents an unknown cross-reactive material, the exciting finding will persist that mouse horizontal cells are immunologically different at early and late developmental stages. Any material which is so strongly expressed transiently during development will be of interest. These various possibilities cannot be differentiated until biochemical studies are done to determine whether developing horizontal cells can and do synthesize GABA.

Whatever the role of GAD-like-immunoreactive material in the horizontal cells of the developing mouse retina might be, it is clear that mammalian retinal differentiation does not necessarily depend on a stage at which horizontal cells contain GAD-like-immunoreactive material. One of us studied rat retinal development using the same immunocytochemical approach to localize GAD-positive cells. Developmental stages comparable to those illustrated here for the mouse were studied, and no GAD-positive horizontal cells were observed $(J$. Schnitzer, unpublished results). Lam et al. (1980) and Fung et al. (1982) have used $\left[{ }^{3} \mathrm{H}\right] \mathrm{GABA}$ uptake studies in the developing rabbit retina and have not found GABAergic horizontal cells. Although it is still possible that immunocytochemical experiments might reveal GAD expression during rabbit retinal development, it is clear that the rat at least does not have the same immunoreactive components in its horizontal cells as does the mouse. This fact leaves us with the intriguing search for the function of this transient factor in the development of mouse horizontal cells.

\section{References}

Bhattacharjee, J. (1977) Sequential differentiation of retinal cells in the mouse studied by diaphorase staining. J. Anat. 123: 273-282.

Blanks, J. C., and D. Bok (1977) An autoradiographic analysis of postnatal cell proliferation in normal and degenerative mouse retina. J. Comp. Neurol. 174: 317-328. 
Blanks, J. C., and S. Roffler-Tarlov (1982) Differential localization of radioactive gamma-aminobutyric acid and muscimol in isolated and in vivo mouse retina. Exp. Eye Res. 35: 573-584.

Brandon, C., D. M. K. Lam, and J. -Y. Wu (1979) The $\gamma$-aminobutyric acid system in rabbit retina: Localization by immunocytochemistry and autoradiography. Proc. Natl. Acad. Sci. U. S. A. 76: 3557-3561.

Brandon, C., D. M. K. Lam, Y. Y. T. Su, and J. -Y. Wu (1980) Immunocytochemical localization of GABA neurons in the rabbit and frog retina. Brain Res. Bull. 5: 21-29.

Drager, U. C. (1983) Coexistence of neurofilaments and vimentin in a neurone of adult mouse retina. Nature 303: 169-172.

Ehinger, B. (1970) Autoradiographic identification of rabbit retinal neurons that take up GABA. Experientia 26: 1063-1064.

Ehinger, B. (1982) Neurotransmitter systems in the retina. Retina 2 : 305-321.

Ehinger, B., and B. Falck (1971) Autoradiography of some suspected neurotransmitter substances: GABA, glycine, glutamic acid, histamine, dopamine, and L-dopa. Brain Res. 33: 157-172.

Fisher, L. J. (1979a) Development of synaptic arrays in the inner plexiform layer of neonatal mouse retina. J. Comp. Neurol. 187: 359372.

Fisher, L. J. (1979b) Interplexiform cell of the mouse retina: A Golgi demonstration. Invest. Ophthalmol. Vis. Sci. 18: 521-523.

Fung, S. -C., Y. -C. Kong, and D. M. K. Lam (1982) Prenatal development of GABAergic, glycinergic, and dopaminergic neurons in the rabbit retina. J. Neurosci. 2: 1623-1632.

Hinds, J. W., and P. L. Hinds (1974) Early ganglion cell differentiation in the mouse retina: An electron microscopic analysis utilizing serial sections. Dev. Biol. 37: 381-416.

Hinds, J. W., and P. L. Hinds (1978) Early development of amacrine cells in the mouse retina: An electron microscopic, serial section analysis. J. Comp. Neurol. 179: 277-300.

Hinds, J. W., and P. L. Hinds (1979) Differentiation of photoreceptors and horizontal cells in the embryonic mouse retina: An electron microscopic, serial section analysis. J. Comp. Neurol. 187: 495-512.

Hinds, J. W., and P. L. Hinds (1983) Development of retinal amacrine cells in the mouse embryo: Fvidence for two modes of formation. I. Comp. Neurol. 213: 1-23.

Hollyfield, J. G., M. E. Rayborn, P. V. Sarthy, and D. M. K. Lam (1979) The emergence, localization and maturation of neurotransmitter systems during development of the retina in Xenopus laevis. J. Comp. Neurol. 188: 587-598.

Lam, D. M. K., S. -C. Fung, and Y. -C. Kong (1980) Postnatal development of GABA-ergic neurons in the rabbit retina. J. Comp. Neurol. 193: 89-102.

Landis, S. C., and D. Keefe (1983) Evidence for neurotransmitter plasticity in vivo: Developmental changes in properties of cholinergic sympathetic neurons. Dev. Biol. 98: 349-372.

Le Douarin, N. M., M. A. Teillet, C. Ziller, and J. Smith (1978) Adrenergic differentiation of cells of the cholinergic ciliary and Remak ganglia in avian embryo after in vivo transplantation. Proc. Natl. Acad. Sci. U. S. A. 75: 2030-2034.

Madtes, P. C., and D. A. Redburn (1983) Synaptic interactions in the GABA system during postnatal development in retina. Brain Res. Bull. 10: 741-745.

Marshall, J., and M. J. Voaden (1974a) An investigation of the cells incorporating ${ }^{3} \mathrm{H}$-GABA and ${ }^{3} \mathrm{H}$-glycine in the isolated retina of the rat. Exp. Eye Res. 18: 367-370.

Marshall, J., and M. J. Voaden (1974b) An autoradiographic study of the cells accumulating ${ }^{3} \mathrm{H} \gamma$-aminobutyric acid in the isolated retinae of pigeon and chicken. Invest. Ophthalmol. 13: 602-607.

Marshall, J., and M. Voaden (1975) Autoradiographic identification of the cells accumulating ${ }^{3} \mathrm{H} \gamma$-aminobutyric acid in mammalian retinae: A species comparison. Vision Res. 15: 459-461.

Nakamura, Y., B. A. McGuire, and P. Sterling (1980) Interplexiform cell in cat retina: Identification by uptake of $\gamma-{ }^{3}(\mathrm{H})$ aminobutyric acid and serial reconstruction. Proc. Natl. Acad. Sci. U. S. A. 77: $658-661$

Neal, M. .I., and I. I. Iversen (1972) Autoradiographic localization of ${ }^{3} \mathrm{H}$-GABA in rat retina. Nature New Biol. 235: 217-218.

Oertel, W. H., D. E. Schmechel, M. L. Tappaz, and I. J. Kopin (1981a) Production of a specific antiserum to rat brain glutamic acid decarboxylase by injection of an antigen-antibody complex. Neuroscience 6: $2689-2700$.

Ocrtel, W. H., D. E. Schmechel, V. K. Weise, D. H. Ransom, M. L. Tappaz, H. C. Krutzsch, and I. J. Kopin (1981b) Comparison of cysteine sulphinic acid decarboxylase isoenzymes and glutamic acid decarboxylase in rat liver and brain. Neuroscience 6: 2701-2714.

Oertel, W. H., D. E. Schmechel, E. Mugnaini, M. L. Tappaz, and I. J. Kopin (1981c) Immunocytochemical localization of glutamate decarboxylase in rat cerebellum with a new antiserum. Neuroscience 6 : $2715-2735$.

Oertel, W. H., D. E. Schmechel, and E. Mugnaini (1983) Glutamic acid decarboxylase (GAD): Purification, antiserum production, immunocytochemistry. In Current Methods in Cellular Neurobiology. Vol. 1: Anatomical Techniques, J. L. Barker and J. McKelvy, eds., pp. 63110 , John Wiley \& Sons, Inc., New York.

Olney, J. W. (1968) An electron microscopic study of synapse formation, receptor outer segment development, and other aspects of developing mouse retina. Invest. Ophthalmol. 7: 250-268.

Patterson, P. H. (1978) Environmental determination of autonomic neurotransmitter functions. Annu. Rev. Neurosci. 1: 1-17.

Pourcho, R. G. (1980) Uptake of $\left({ }^{3} \mathrm{H}\right)$ glycine and $\left({ }^{3} \mathrm{H}\right) \mathrm{GABA}$ by amacrine cells in the cat retina. Brain Res. 198: 333-346.

Ramón y Cajal, S. (1960) Development of the horizontal neurons in the mouse retina and their accidental alteration of location and direction. In Studies on Vertebrate Neurogenesis, L. Guth, transl., pp. 380 401, Charles C Thomas, Publisher, Springfield, IL.

Shaw, G., and K. Weber (1983) The structure and development of the rat retina: An immunofluorescence microscopical study using antibodies specific for intermediate filament proteins. Eur. J. Cell Biol. 30: $219-232$.

Sidman, R. L. (1961) Histogenesis of mouse retina studied with thymidine- $\mathrm{H}^{3}$. In The Structure of the Eye, G. K. Smelser, ed., pp. 487506, Academic Press, Inc., New York.

Sternberger, L. A. (1979) Immunocytochemistry, Ed. 2, John Wiley \& Sons, Inc., New York.

Vaughn, J. E., E. V. Famiglietti, Jr., R. P. Barber, K. Saito, E. Roberts, and C. E. Ribak (1981) GABAergic amacrine cells in rat retina: Immunocytochemical identification and synaptic connectivity. J. Comp. Neurol. 197: 113-127.

Wässle, H., L. Peichl, and B. B. Boycott (1978) Topography of horizontal cells in the retina of the domestic cat. Proc. R. Soc. Lond. Biol. 203: 269-291.

West, R. W. (1976) Light and electron microscopy of the ground squirrel retina: Functional considerations. J. Comp. Neurol. 168: $355-378$.

Wu, J. - Y. (1982) Purification and characterization of cysteic acid and cysteine sulfinic acid decarboxylase and L-glutamate decarboxylase from bovine brain. Proc. Natl. Acad. Sci. U. S. A. 79: 4270-4274.

Wu, J. -Y., C. Brandon, Y. Y. T. Su, and D. M. K. Lam (1981) Immunocytochemical and autoradiographic localization of GABA system in the vertebrate retina. Mol. Cell. Biochem. 39: 229-238.

Zucker, C. L., S. Yazulla, and J. -Y. Wu (1983) Non-correspondence of ${ }^{3}$ H-GABA uptake and GAD localization: Two potential markers of GABAergic amacrine cells in goldfish retina. Soc. Neurosci. Abstr. 9: 723 . 